$\mathrm{Oz}$

$1-1-1985$

\title{
Process and Collaboration: Two Competitions: Monroeville Civic Center/Hong Kong Peak
}

Alex Krieger

Follow this and additional works at: https://newprairiepress.org/oz

(c) (i) $\Theta \Theta$

This work is licensed under a Creative Commons Attribution-Noncommercial-No Derivative Works 4.0 License.

\section{Recommended Citation}

Krieger, Alex (1985) "Process and Collaboration: Two Competitions: Monroeville Civic Center/Hong Kong Peak," Oz: Vol. 7. https://doi.org/10.4148/2378-5853.1093

This Article is brought to you for free and open access by New Prairie Press. It has been accepted for inclusion in Oz by an authorized administrator of New Prairie Press. For more information, please contact cads@k-state.edu. 


\title{
Process and Collaboration: Two Competitions
}

\author{
Monroeville Civic Center/Hong Kong Peak
}

Alex Krieger

I work with a partner, Lawrence Chan. Therefore, this essay is about a thought process which is the product of a collaboration. Though no less subject to individual initiative, whimsy, and trail and error, working in partnership demands common purposes. I shall attempt to describe these and how they were brought to bear on two projects.

The projects are both competition entries, one for the Monroeville Civic Center Competition, and the other for the Hong Kong 'Peak' Competition (Fig. $1 \& 2$ ). Freer from the constraints imposed by daily practice, competitions offer necessary opportunities for experiment and speculation, but they may also serve as a means to pursue particular objectives, a kind of exercise in disciplining one's thoughts. These two competitions attracted us because of their complex programs.

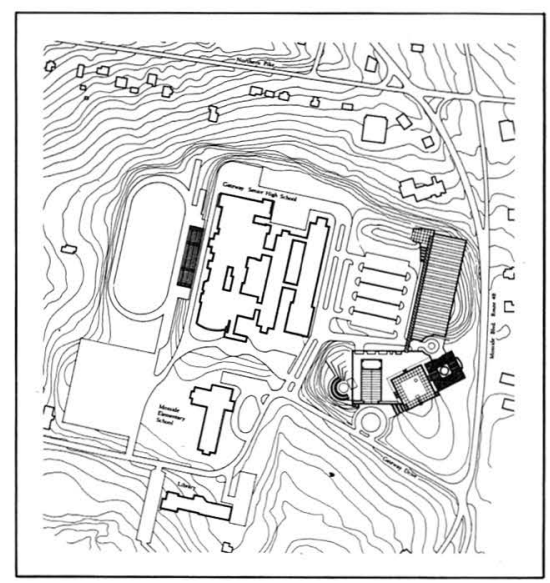

1. Site Plan -

Monroeville Competition,

16

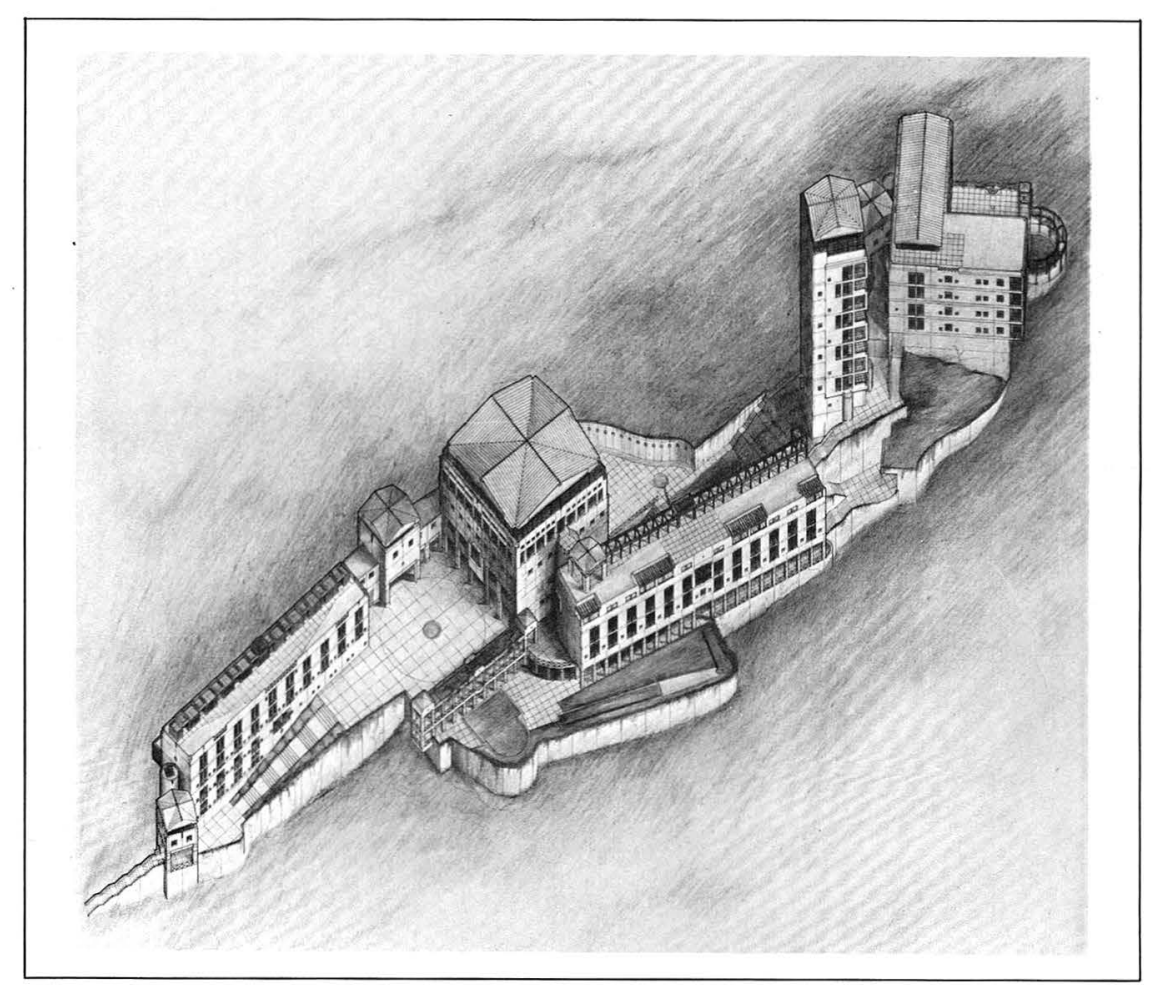

2. Axonometric View - Peak Competition, Hong Kong. 1982.

engaging sites, and provocative (some would even say ambiguous) purposes. While not tested by construction, Monroeville and the Peak illustrate several of our long standing design concerns: an emphasis on shaping that which is public while balancing collective order and individual identity, the seeking of composite forms between artifact and fabric, and the fostering of associations to place and form in order to approach an architecture which Joseph Hudnot once called the ". . . outward frame and envelope of a communal life."
Both projects also afforded the pursuing of another of our frequent preoccupations-speculating on the nature by which a particular institution should present itself and contribute to the public realm. Monroeville called for the design of a town hall, a performing arts center, and an athletic center as one integrated facility for a suburban community twenty miles east of Pittsburg. The site was a pair of scraggly knolls between several strip. Thus, Monroeville presented the challenge of defining 'civic center' within the characteristically suburban, district schools and a commercial strip-dominated context. How should one organize or, dare say, even elevate a collection of public uses that in a suburban context are commonly dissegregated and typically lacking any civic ambition

The Peak called for the improbable combination of a social club with thirty guest suites, dining and sporting facilities, four private residences for an extended family which would share a communal dining hall; and four condominiums, clearly a means of financing the remainder of the compound. The site was dramatic and prominent-on Victoria Peak overlooking Honk Kong harbor. Thus, the Peak presented the challenge of locating a private, self-serving institution on an extemely visible, even monumental, site. How could the desired generosity, luxuriousness, and order be achieved while avoiding pomposity, or worse, implying civic significance out of proportion to the nature of the institution?

In struggling to identify an appropriate form for an institution, and in the absence of compelling reasons to disregard convention, we generally give weight to its public purposes, elaborating its responsibilities to a larger environment. In Monroeville, characterized as other mid-twentieth century suburbs by an absence of civic space, we sought to enhance municipal functions by establishing a nobler focus of citizen activity. A formal group, consisting of the town hall 


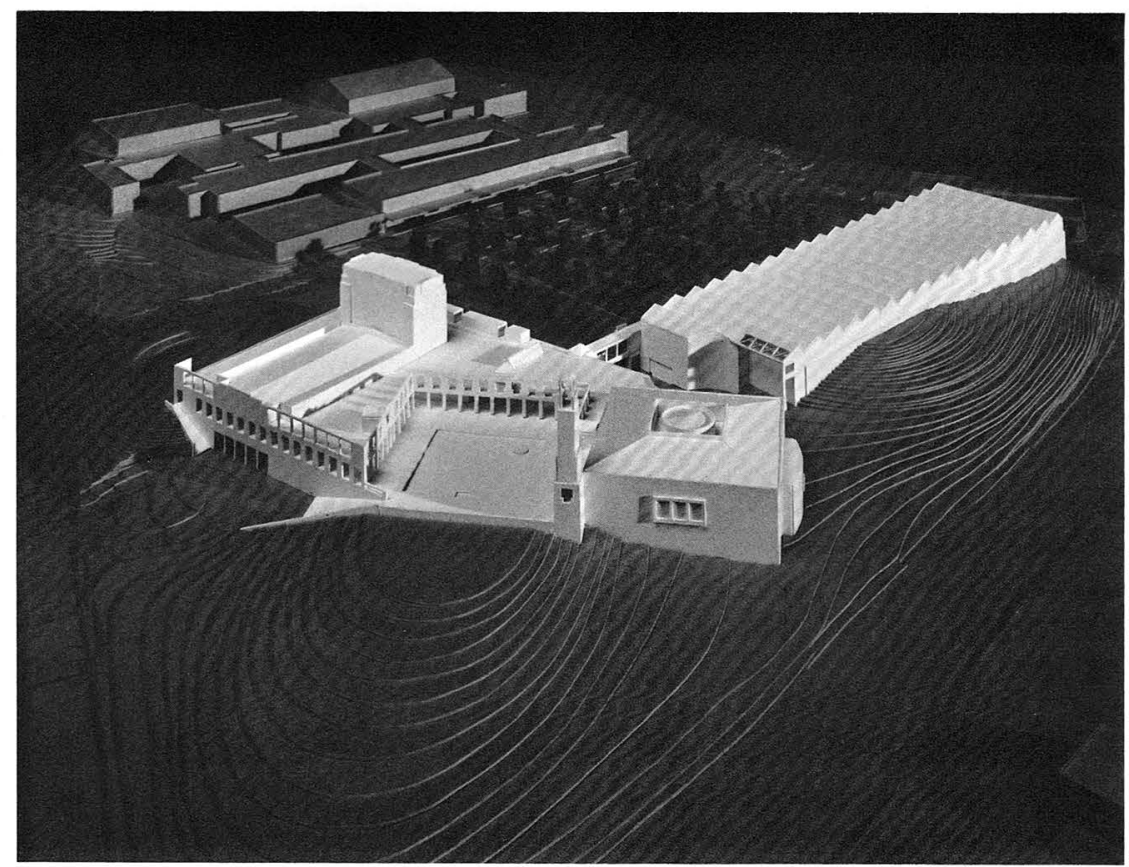

3. Main Entrance of Civic Center.

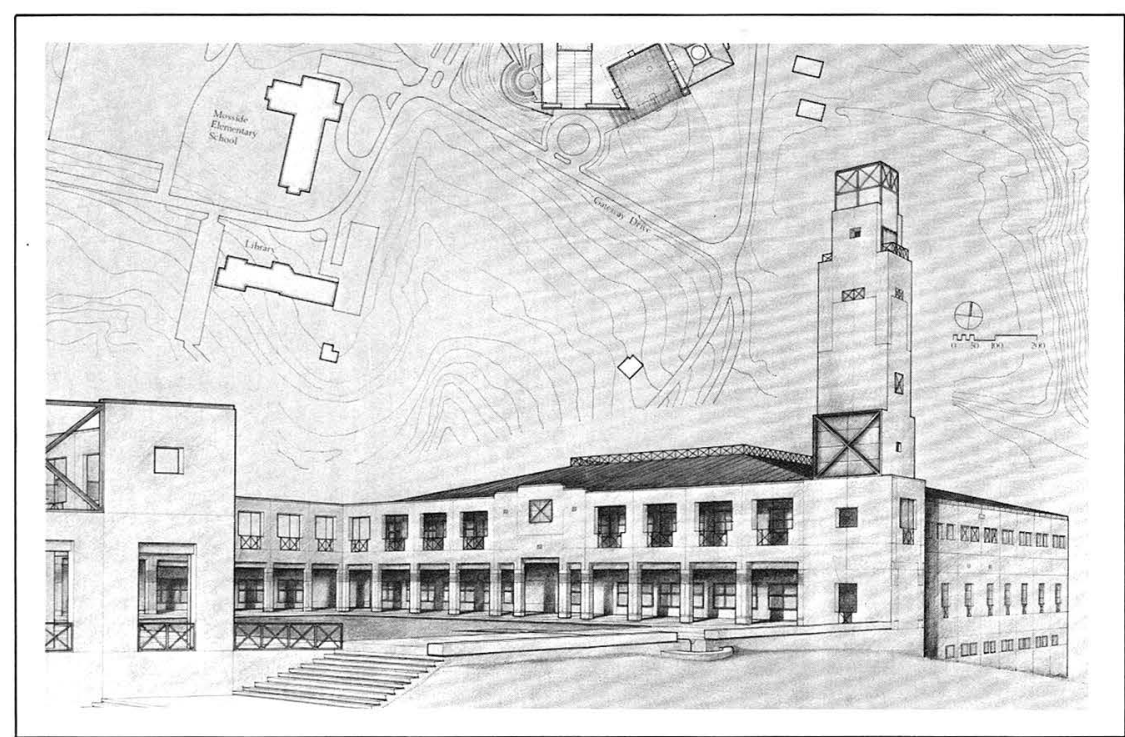

4. Entrance Court.

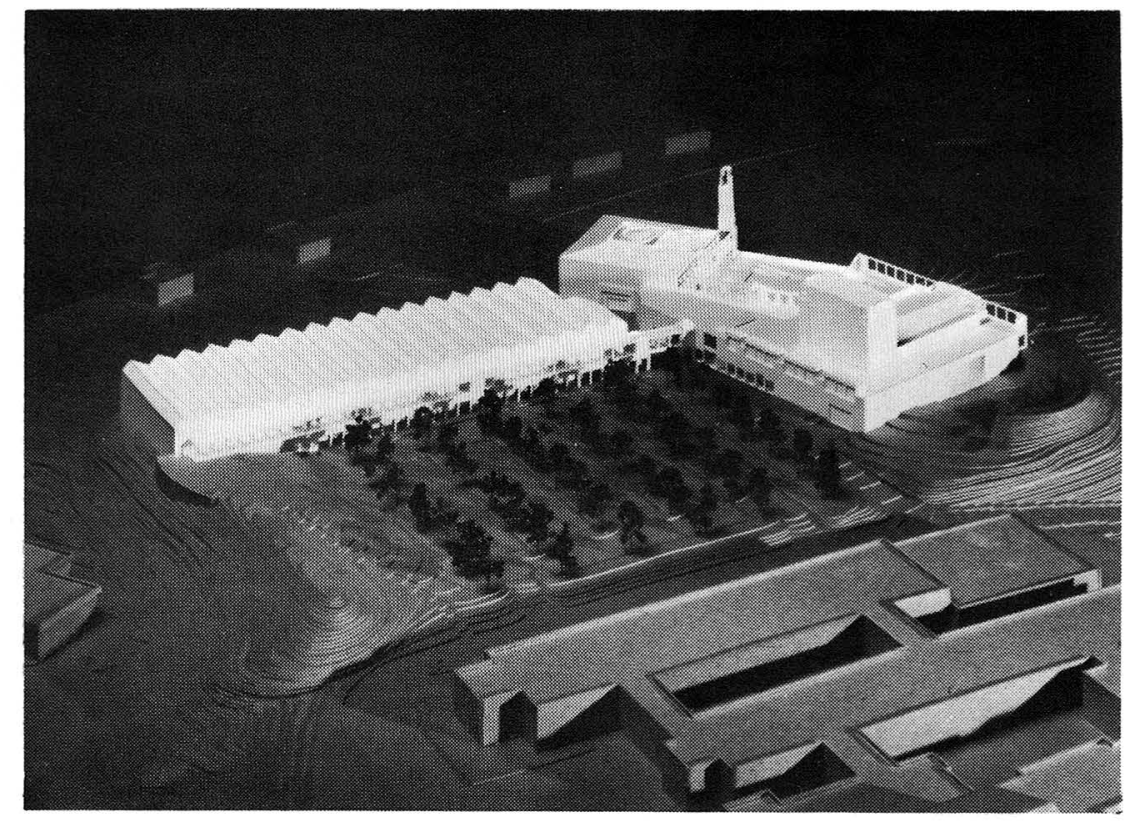

5. Parking Quadrangle between School and Sports Center.

and arts center, forms a ceremonial courtyard perched on a gently sloping knoll overlooking the main entrance to the site (Fig. 3). In recognition of the tradition established at Jefferson's campus in Virginia, the space has an open end, extending toward the landscape. Marked by a bell tower, the grouping fosters an image of a Capitoline Hill, a civic place (Fig. 4). The sports center, cut into the back knoll to reduce its bulk, helps to define a parking quadrangle behind the civic group (Fig. 5). Its principal elevation is towards the parking and consists of an arcade which extends under a portal to the civic group and continues around the perimeter of the courtyard. This arcade, the upper

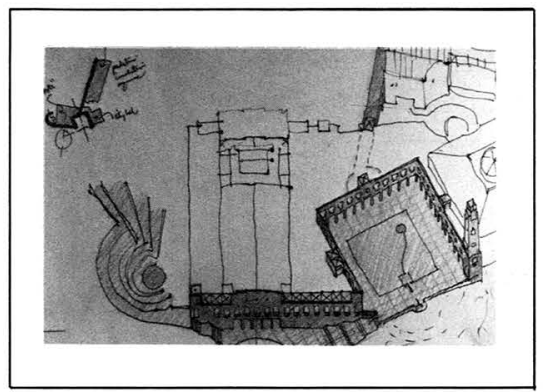

6. Sketches of entrance procession.

level of which is open to the sky. serves as a collector and a common lining. It helps to aggrandize the place, a bit like the exaggerated storefronts of a western Main Street. The presentation of an order ensemble is outward befitting a public place. (Fig. 6). 


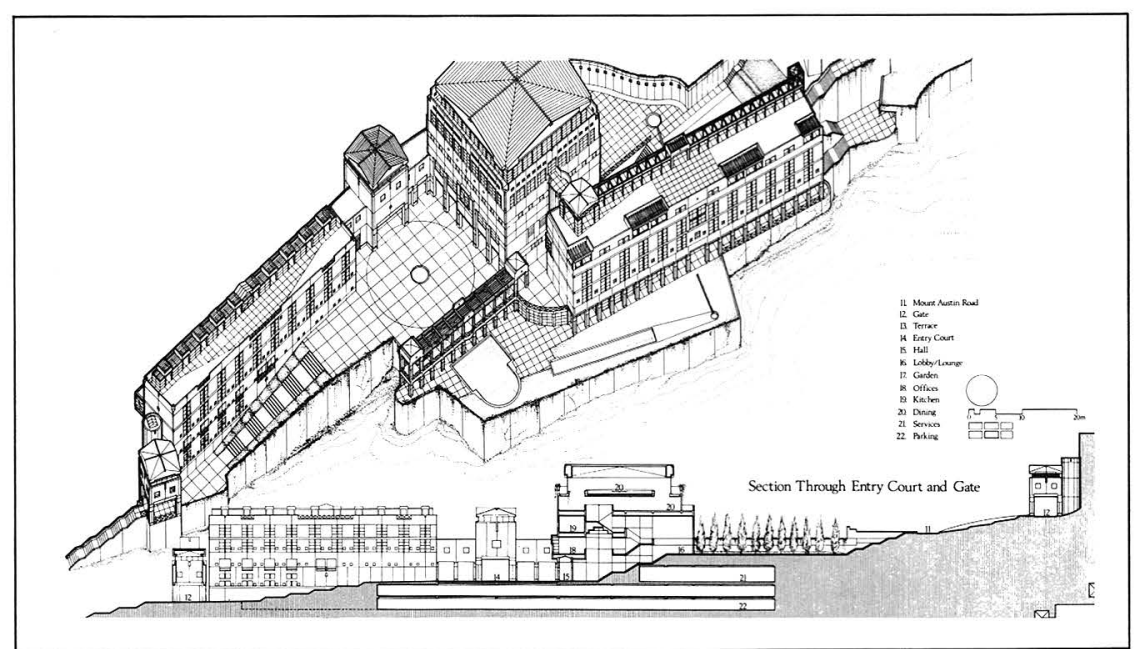

7. Axonometric and Section of Peak Competition.

By contrast, the perimeter of the Peak, a private place, is self-effacing and circumstancial. It is a series of articulated walls and gate houses following the alignment of the single street which adjoins the site. We felt compelled to present the place as ordinary. perhaps dampening the promoter's wishes for a dramatic silhouette for their club. The grouping helps to form the street; only internally - at the precinct of the clubhouse-does a more exhuberent collection of terraces and gardens burst forth (Fig. 7) The club members may carouse about at will without overwhelming the street or the adjacent residences. Within the compound a further demarcation exists between the public club functions and the private residential areas. The former are entered through their principal open spaces. On the other hand, the courtyard of the family residences is sheltered from the entry gate, reflec- profile of the overall scheme is punctured only by a tower which contains the four speculative condominiums. Marked by a tower of condominiums whose mortgages support the the institution are tempered (Fig. 8)

Because we try to adhere to the conventions of public/private, we shy away from the easy-and false-dichotomy of object vs. fabric We admire the monastic compounds of medieval France and the Alcazars of Hispano-Moorish Spain precisely because they cannot be so easily categorized. Our favorite buildings tend to be figure and fragment emerging as figure at the appropriate moment while helping to shape a larger fabric. In the company of its neighbors, whom it respects, the Palazzo Borghese forgoes a typological purity, and contorts its perimeter to conform to a fabric. This does not preclude its making a facade pleasures of the club, the pretenses of

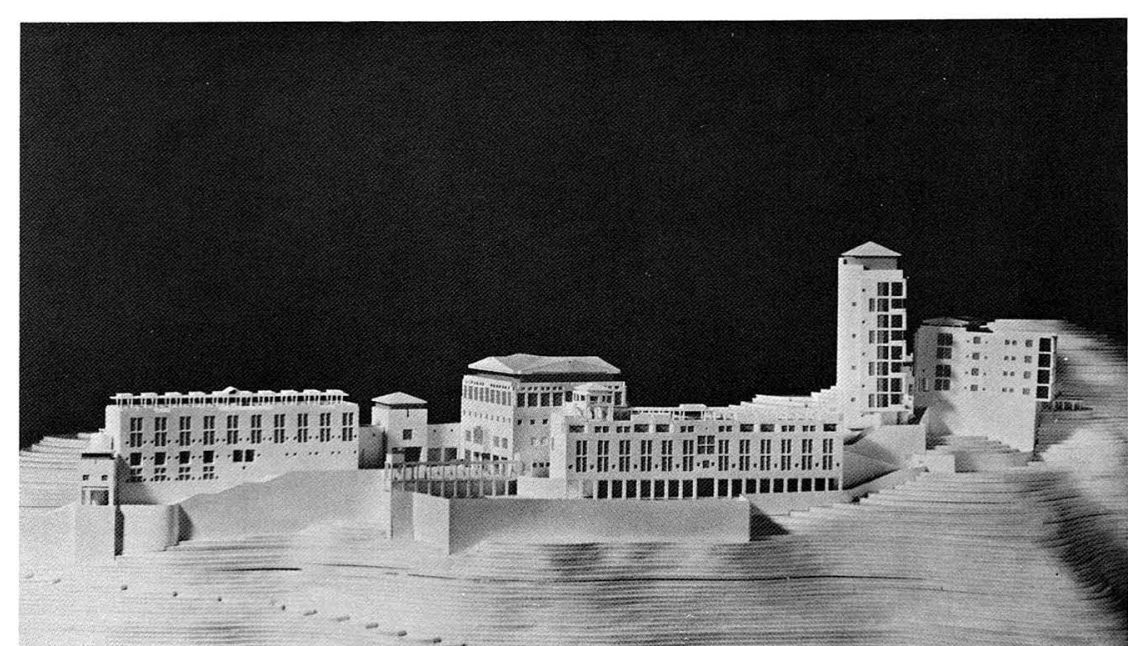

8. Northeast view of Peak Competition. toward the Piazza Borghese, and even a second more lyrical one to the River Tiber.

While planning Monroeville and the Peak, we sought to achieve such a composite order. The organization of buildings and spaces attempts to form a network (Fig. $9 \&$ 10). The perception of the primacy of building versus the primacy of space often shifts as one meanders through the plan. From certain vantage points individual buildings recede to become edges which define spaces. The clubhouse at the Peak, the center of the composition, virtually is at once object and background to the principal arrival court (Fig. 11). In Monroeville, the arts center and town hall seem from a distance to be independent and distinct, yet at the courtyard level they are joined and share a common language of wall surface and openings (Fig. 12). Such a composite order was commonplace before the solitary ar- tifact took precedence in the urban landscape. Seeking to re-dress this imbalance, to accommodate in dividual prerogative within a common framework rather than celebrating the former at the expense of the latter, seems an urgent task of contemporary urban architecture.

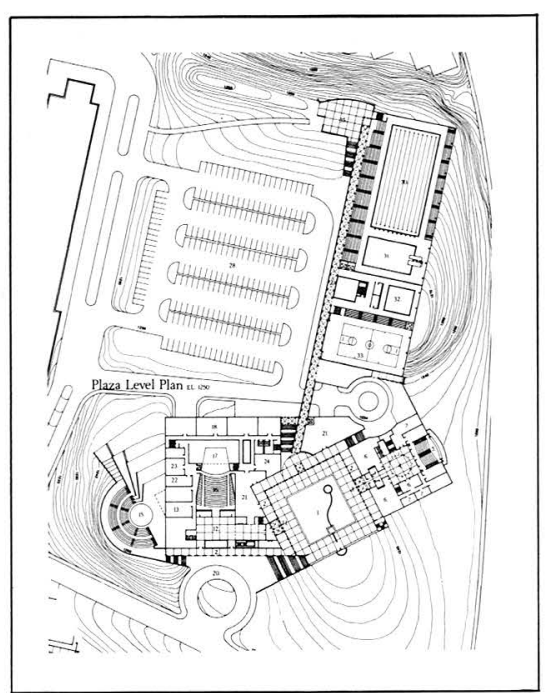

9. Plaza Level Plan of Monroeville 


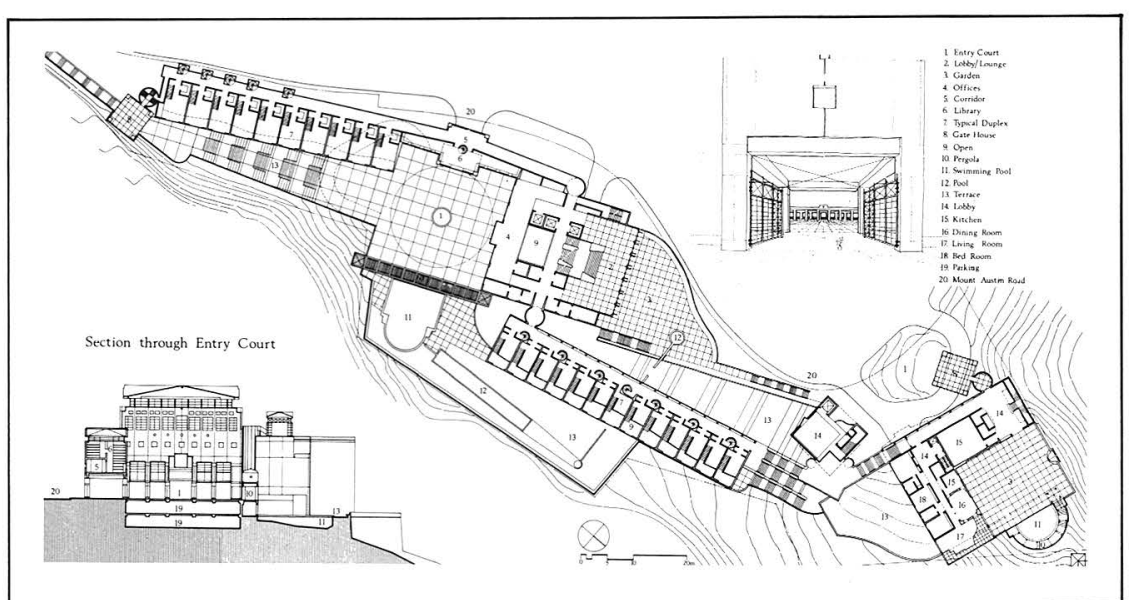

10. Principle Plan and entry section of Peak Competition.

Having described some of our objectives, I must articulate some of our beliefs. For us, architecture remains the Mumfordian 'house for man,' and therefore we strive to ennoble man's condition and celebrate man's spirit more often than we seek to be rhetorical towards humanity or its institutions. The likely - and not only intended-consequences of design decisions are of concern to us; the realms of experience and perception are as important as the realm of in tellectual precept. We therefore consider the exercise of judgement as important to the design process as the exercise of ideology. We remain skeptical of the impulse to build the theory, which frequently leads merely to lavish indulgence. To paraphrase a position recently expressed by Gerhard Kallman, we consider our theories a kind of scaffolding: they are essential to forming a design (or a construction) and then give way to the phenomenon and perceptions

delivered by the product. Being a sentual art, architecture (whether building or representation) cannot but achieve a measure of autonomy from the thought process which shaped it. In the experience of its inhabitants, critics, and admirers, a work of architecture transcends the limitations of a theory and indeed serves to shape subsequent theories.

Finally, we try not to confuse means and ends. We lean toward words such as essence and coherence, but remain cognizent of the double meanings of such alluring words as complexity, juxtaposition, paradox, ambiguity, and dialectic. In common usage, the dialectic seems to refer only to the identification of juxtaposed or contradictory ideas, as if that in itself is a virtue. It may be in its classical definition, a dialectic is a theory of weighing oppositions for the purpose of reconciliation, or arriving at some truth. Similarly, in architecture, the presen-

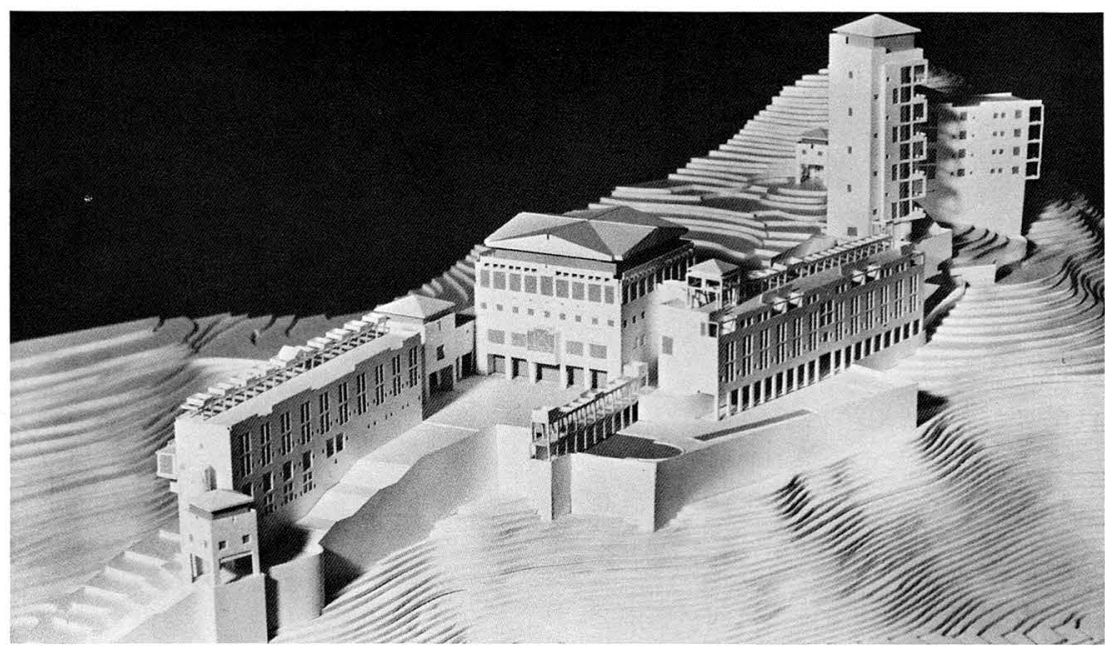

11. Entrance Court of Peak Competition.

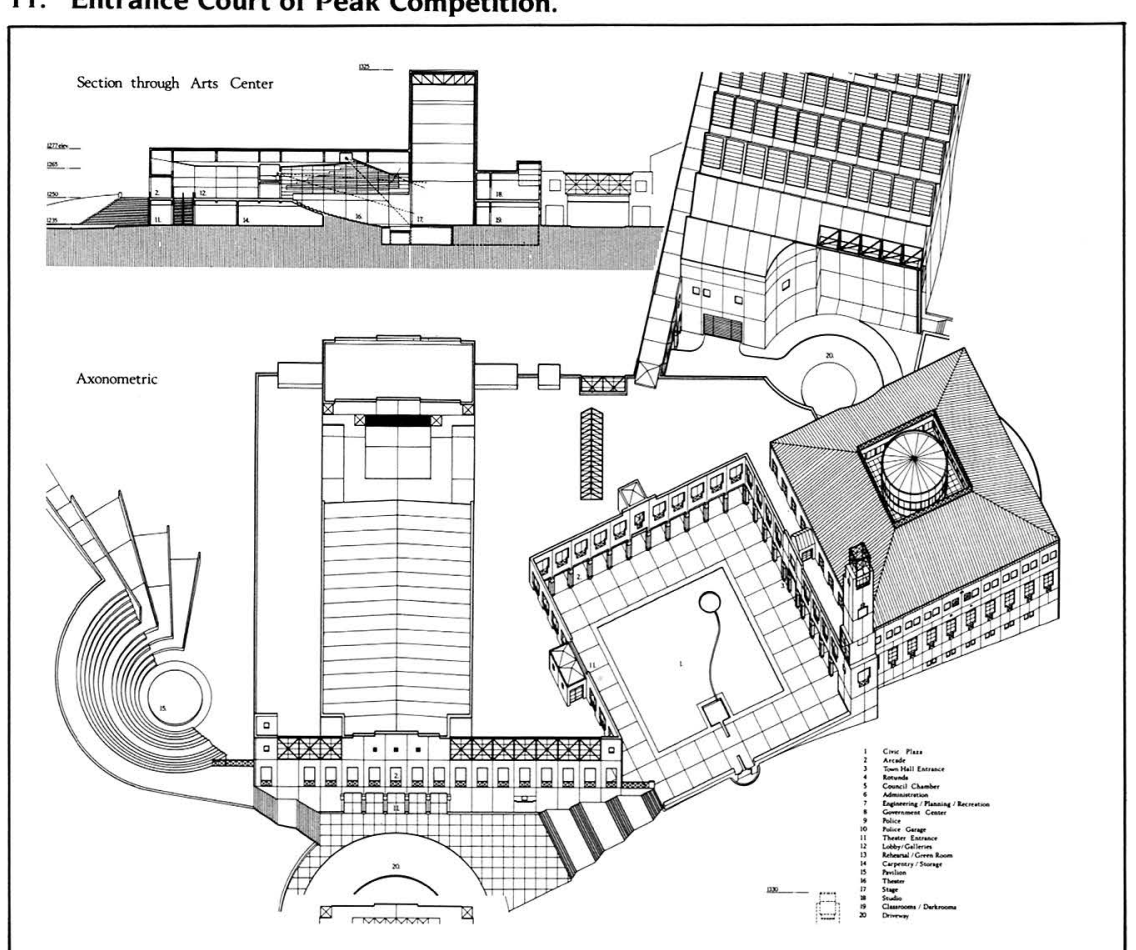

12. Axonometric of Civic Complex in Monroeville Competition.

tation of complexity is not enough. To establish and to form are among the roles of architecture, which in a small and large ways diminish ambiguity, and certainly the ambiguities of amorphousness. 